\section{Case Reports in Dermatology}

Case Rep Dermatol 2017;9:130-135

DOI: 10.1159/000477961

Published online: August 17, 2017
(C) 2017 The Author(s)

Published by S. Karger AG, Basel www.karger.com/cde

This article is licensed under the Creative Commons Attribution-NonCommercial 4.0 International License (CC BY-NC) (http://www.karger.com/Services/OpenAccessLicense). Usage and distribution for commercial purposes requires written permission.

\title{
Verruciform Xanthoma of a Lower Lip Lesion: A New Case and Review of the Literature
}

\author{
Filiz Cebeci $^{a} \quad$ Ayşegül Verim $^{b} \quad$ Adnan Somay $^{c}$ Emel Çalıkoğlu $^{d}$
}

${ }^{a}$ Department of Dermatology, Istanbul Medeniyet University, Goztepe Training and Research Hospital, Istanbul, Turkey; ${ }^{\mathrm{b}}$ Department of Otorhinolaryngology/Head and Neck Surgery, Haydarpaşa Numune Training and Research Hospital, Istanbul, Turkey; 'Department of Pathology, Fatih Sultan Mehmet Training and Research Hospital, Istanbul, Turkey; ${ }^{\mathrm{d}}$ Department of Dermatology, Near East University Faculty of Medicine, Nicosia, Cyprus

\section{Keywords}

Lip diseases · Verruciform xanthoma

\begin{abstract}
A non-smoking man in his seventh decade presented with a lesion he had had for about 5 years on the right external surface of the lip $1 \mathrm{~mm}$ from the vermilion border. On physical examination, a yellowish-coloured, non-tender, verrucous mass of $0.5 \times 0.7 \mathrm{~cm}$ was observed. A histopathological examination of the first 3-mm punch biopsy was non-diagnostic. The histopathological evaluation of a second, 5-mm-deep punch biopsy made by a pathology expert in oral lesions revealed a diagnosis of verruciform xanthoma. The key to the diagnosis of verruciform xanthoma is to recognize xanthoma cells. However, these cells may be insufficient in number in small and superficial biopsy material and overlooked by a pathologist especially when lacking knowledge of this uncommon lesion. Verruciform xanthoma of the lower lip at the vermilion border is an extremely rare entity described in 5 cases
\end{abstract}


worldwide to date. We aimed to bring verruciform xanthoma to readers' attention for a differential diagnosis of lower lip diseases and to prevent overdiagnosis and overtreatment of this lesion unfamiliar to otorhinolaryngologists.

(C) 2017 The Author(s)

Published by S. Karger AG, Basel

\section{Introduction}

Verruciform xanthoma is an uncommon, benign condition of unknown aetiology. It usually occurs within the oral cavity. Lesions on scrotal or vulvar skin and in other mucocutaneous locations (glottis, larynx, lips, nose, or oesophagus) are less frequently encountered in the literature [1-3]. Although still unclarified, there is speculation on a possible role of immunomodulatory therapy (radiation and chemotherapy) as well as tobacco and snuff use in the aetiopathogenesis of the oral and labial forms $[4,5]$.

Lesions appear as a well-demarcated, soft, painless, sessile, slightly elevated mass with a white, yellow/white, or red colour and a papillary or roughened surface. In the absence of concomitant pathology, this condition is usually asymptomatic. The clinical appearance of verruciform xanthoma is non-diagnostic; the diagnosis is almost always made on histologic examination. It is frequently misdiagnosed on clinical examination of the oral mucosa, i.e., as squamous papilloma, verruca vulgaris, or verrucous carcinoma [4].

Biopsy may be the only means by which to determine the diagnosis. The histopathology of the lesion is characterized by hyperparakeratosis, acanthosis, and elongation of the rete ridges. Histomorphologically, the lesion has a verrucous, papillary, and flat pattern. The presence of large, vacuolated foam cells (xanthoma cells), originating from lipid-containing macrophages, within the connective tissue papillae and epithelium is definitive for a diagnosis [5]. Although not infrequently located at mucocutaneous junctions, verruciform xanthoma affecting the vermilion border of the lip is very rarely reported. To date only 5 cases of verruciform xanthoma on the vermilion border of the lower lip have been reported in the English-language literature [1-3]. Here we present a case of verruciform xanthoma involving the vermilion border of the right external surface of the lower lip so as to report this very rare entity and discuss the microscopic features, prevalence, and differential diagnoses in a survey of the literature.

\section{Case Report}

A 61-year-old man (non-smoking) presented with a lesion on the right external surface of the lip $1 \mathrm{~mm}$ from the vermilion border. The patient's medical history revealed that he had had the lesion for about 5 years. On physical examination, a yellowish-coloured, broadbased, non-tender, verrucous mass of $0.5 \times 0.7 \mathrm{~cm}$ was observed (Fig. 1). There was no other accompanying mucosal lesion on endoscopic examination of the oropharynx, nasopharynx, and larynx. No pathologic cervical lymph node was noticed on palpation. Laboratory tests including blood lipid profiles were within normal range and a serologic syphilis test was negative. A 3-mm punch biopsy was taken from the lesion. Microscopic examination re- 
Cebeci et al.: Verruciform Xanthoma of a Lower Lip Lesion: A New Case and Review of the Literature

vealed fibrous connective tissue under the stratified squamous epithelium, flattened rete pegs, and hyperkeratosis. The patient was diagnosed with irritation fibroma.

The patient, who refused excisional biopsy, was enrolled in a follow-up programme. After 1 year, the patient was referred to the clinic and a 5-mm punch biopsy was subsequently performed. This time, the histopathological findings were consistent with verruciform xanthoma: parakeratosis of the squamous epithelium, hyperkeratosis, papillomatosis, verruciform acanthosis, regularly elongated rete ridges (Fig. 2a), presence of neutrophils in the keratin layer, infiltration of xanthomatous cells with large vacuolated cytoplasm and small nuclei in the papillary dermis, and mononuclear inflammatory cell infiltration of the reticular dermis (Fig. 2b). There was no cytological atypia. CD68 showed strong cytoplasmic immunostaining in the foam cells (Fig. 2c).

A third biopsy revealed the diagnosis of verruciform xanthoma (Fig. 2). Based on the definitive diagnosis of verruciform xanthoma, the lesion was treated by complete excision without complications. The final diagnosis of verruciform xanthoma was confirmed by microscopic evaluation of excisional biopsy specimen. Polymerase chain reaction amplification of HPV was negative in the lesion of the patient. There was no recurrence on the side of the lesion at the postoperative 3-year follow-up.

\section{Discussion}

The lips are one of the most common sites of the facial complex exposed to factors (trauma, ultraviolet radiation, tobacco, and food additives) that can damage the tissue structure. Thus numerous lesions including inflammatory processes and benign and malignant tumours may be seen in this area. In an article [6] including 1,034 lip lesions, reactive/inflammatory lesions are reported to represent the largest number of pathologies (59.5\%), followed by malignant/dysplastic lesions (21.7\%) and benign tumours (19.1\%). The most commonly diagnosed lesion of the lower lip is mucocoele. As benign lesions, haemangioma, squamous papilloma, and naevocellular naevus are seen in the lower lip, with an incidence of $51.3,21.3$, and $11.7 \%$, respectively. Squamous papilloma is commonly defined in patients especially in their sixth decade of life. Among reactive/inflammatory lesions, mucocoele - mainly seen in young patients - is the most prevalent, followed by fibrous hyperplasia (fifth decade), fibroma (fifth decade), pyogenic granuloma (second decade), and lichen planus (sixth decade) occurring mostly in the lower lip [7].

Knowledge of the most frequent lesions and their prevalence is considered relevant in the diagnostic process. However, no information is available about the prevalence of verruciform xanthoma, despite the existence of a detailed literature survey of a large series of lip lesions [8]. Verruciform xanthoma is very rarely reported on the cutaneous surface of the lower lip. There are only 5 articles published in the English-language literature. This study reports the sixth case of cutaneous verruciform xanthoma of the lower lip published worldwide to date $[1-3,9,10]$. We present the characteristics of these cases with addition of the present study in Table 1.

The main microscopic findings in verruciform xanthoma are parakeratosis of varying degree displaying a typical orange colour on HE staining overlying the hyperplastic epithelium with elongated rete pegs. The presence of foam cells or lipid-laden macrophages in the 
connective tissue papillae is the only hallmark that distinguishes the lesion from squamous papilloma, verruca vulgaris, fibroma, and verrucous carcinoma. This explains why recognition of xanthoma cells on microscopic examination is of the utmost importance for a correct diagnosis [4]. In our case, the microscopic analysis of the first punch biopsy showed evidence of benign cells. In fact, the reason for the present study to make the definitive diagnosis at the second microscopic evaluation was the absence of foamy cells in the first histopathological analysis. This failure is probably due to the fact that only a small and superficial specimen was taken with the 3-mm punch biopsy, where foamy cells are missing.

Since 1997, verruciform xanthoma is classified by the WHO among benign lesions able to microscopically imitate oral squamous cell carcinoma and oral verrucous carcinoma [11]. Consequently, the key to the diagnosis of verruciform xanthoma is to confirm the presence of xanthoma cells to rule out verrucous carcinoma and to prevent overtreatment and excessive surgery. Important steps to overcome the diagnostic pitfalls with regard to verruciform xanthoma are (1) to take sufficient incisional biopsy material (we were unable to perform an incisional biopsy because of the lesion's small size) and (2) to have an oral pathologist perform the histologic evaluation. If properly diagnosed by a pathologist familiar with these lesions, verruciform xanthoma is treated simply by total excision, without recurrence. But if misdiagnosed as a malignancy by a pathologist unfamiliar with this lesion, overtreatment with aggressive surgery is the main danger that a surgeon will have to face [12].

Verruciform xanthoma of the cutaneous part of the lower lip is an extremely rare entity unfamiliar to physicians. The clinical features of the lesion are non-specific and may be misdiagnosed. The key to the diagnosis of verruciform xanthoma is to confirm the presence of xanthoma cells to rule out verrucous carcinoma and to prevent overtreatment and excessive surgery. Its clinical and pathological recognition and correct diagnosis is extremely important. With this report we hope to bring this interesting lesion to readers' attention for a differential diagnosis of lower lip diseases.

\section{Statement of Ethics}

The authors confirm that all the research meets the ethical guidelines, including adherence to the legal requirements, of the study country.

\section{Disclosure Statement}

The authors have no conflicts of interest to disclose. 
Cebeci et al.: Verruciform Xanthoma of a Lower Lip Lesion: A New Case and Review of the Literature

\section{References}

1 Blanco C, Miranda C, Fernández F, Val-Bernal JF, Garijo F, Saiz-Bustillo R: Verruciform xanthoma of the lip: two lesions in a woman. Am J Dermatopathol 1988;10:176-178.

2 Colonna TM, Fair KP, Patterson JW: A persistent lower lip lesion. Verruciform xanthoma. Arch Dermatol 2000;136:665-666.

- 3 Allen CM, Kapoor N: Verruciform xanthoma in a bone marrow transplant recipient. Oral Surg Oral Med Oral Pathol 1993;75:591-594.

-4 Philipsen HP, Reichart PA, Takata T, Ogawa I: Verruciform xanthoma - biological profile of 282 oral lesions based on a literature survey with nine new cases from Japan. Oral Oncol 2003;39:325-336.

5 Nowparast B, Howell FV, Rick GM: Verruciform xanthoma. A clinicopathologic review and report of fifty-four cases. Oral Surg Oral Med Oral Pathol 1981;51:619-625.

Huang CC, Arpey CJ: The lips. Excision and repair. Dermatol Clin 1998;16:127-143.

7 Osterne RL, Costa FW, Mota MR, Vidal Patrocínio RM, Alves AP, Soares EC, et al: Lip lesions in a Brazilian population. J Craniofac Surg 2011;22:2421-2425.

-8 Shulman JD, Beach MM, Rivera-Hidalgo F: The prevalence of oral mucosal lesions in US adults: data from the Third National Health and Nutrition Examination Survey, 1988-1994. J Am Dent Assoc 2004;135:1279-1286.

-9 Archana M, Bahirwani S, Raja JV: A verruciform xanthoma of the lower lip and review of the differential diagnosis. Oral Health Dent Manag 2014;13:712-716.

10 Pereira T, Shetty S, Dodal S, Tamgadge A: Verruciform xanthoma of the lip: a rarity. Indian Dermatol Online J 2016;7:180-182.

11 Pindborg JJ, Reichart PA, Smith CJ, van der Waal I: World Health Organization International Histological Classification of Tumours. Histological Typing of Cancer and Precancer of the Oral Mucosa, ed 2. Berlin/Heidelberg/New York, Springer, 1997, pp 33-40.

12 Mete O, Kurklu E, Bilgic B, Beka H, Unur M: Flat-type verruciform xanthoma of the tongue and its differential diagnosis. Dermatol Online J 2009;15:5.

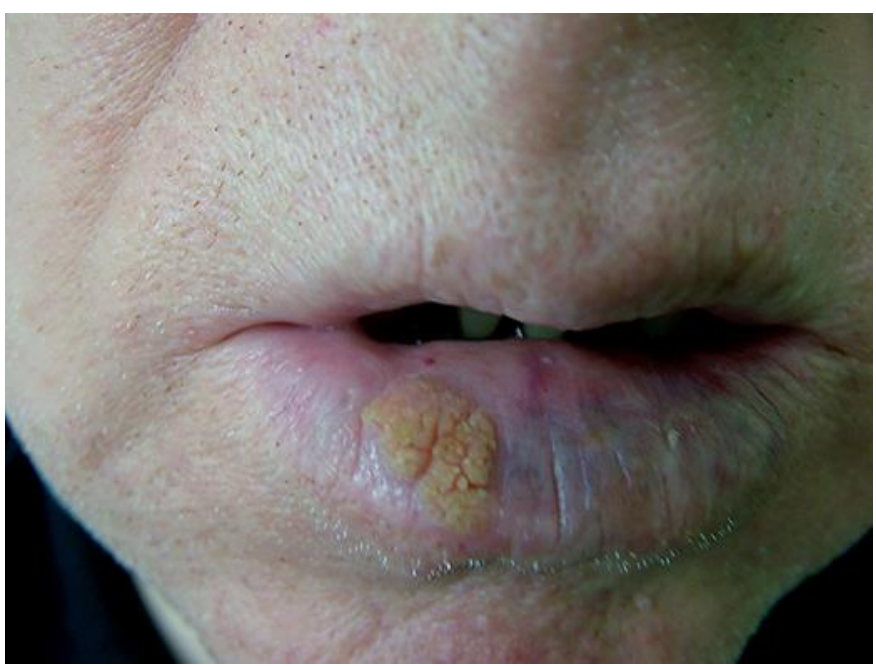

Fig. 1. Verrucous mass of $0.5 \times 0.7 \mathrm{~cm}$ on the right external surface of the lower lip. 

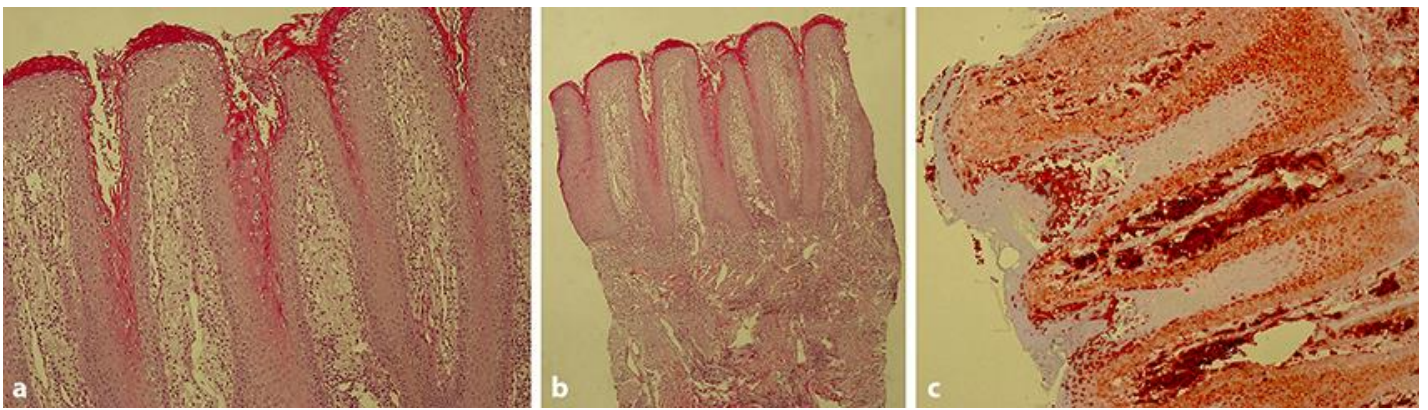

Fig. 2. a Parakeratosis of the squamous epithelium, hyperkeratosis, papillomatosis, verruciform acanthosis, and regularly elongated rete ridges. HE. $\times 40$. b Infiltration of xanthomatous cells with large vacuolated cytoplasm and small nuclei in the papillary dermis and mononuclear inflammatory cell infiltration in the reticular dermis. HE. $\times 100$. c CD68 immunopositivity in xanthoma cells. Immunohistochemical staining. $\times 100$.

Table 1. Detailed analysis of the articles on cutaneous verruciform xanthoma of the lower lip

\begin{tabular}{llllll}
\hline Study & $\begin{array}{l}\text { Patient age, } \\
\text { years }\end{array}$ & $\begin{array}{l}\text { Patient } \\
\text { gender }\end{array}$ & Duration & Diameter & Treatment \\
\hline Blanco et al., 1998 [1] & 60 & female & 2 years & $0.5 \mathrm{~cm}$ & total excision \\
Allen and Kapoor, 1993 [3] & 2 & male & N/D & N/D & N/D \\
Colonna et al., 2000 [2] & 21 & male & 4 years & $3 \times 5 \mathrm{~mm}$ & total excision \\
Archana et al., 2014 [9] & 35 & male & 1.5 years & $1 \times 1 \mathrm{~cm}$ & total excision \\
Pereira et al., 2016 [10] & 59 & male & 8 months & $0.5 \times 1 \mathrm{~cm}$ & total excision \\
Present case, 2017 & 61 & male & 5 years & $4 \times 6 \mathrm{~mm}$ & total excision \\
\hline
\end{tabular}

N/D, not defined. 